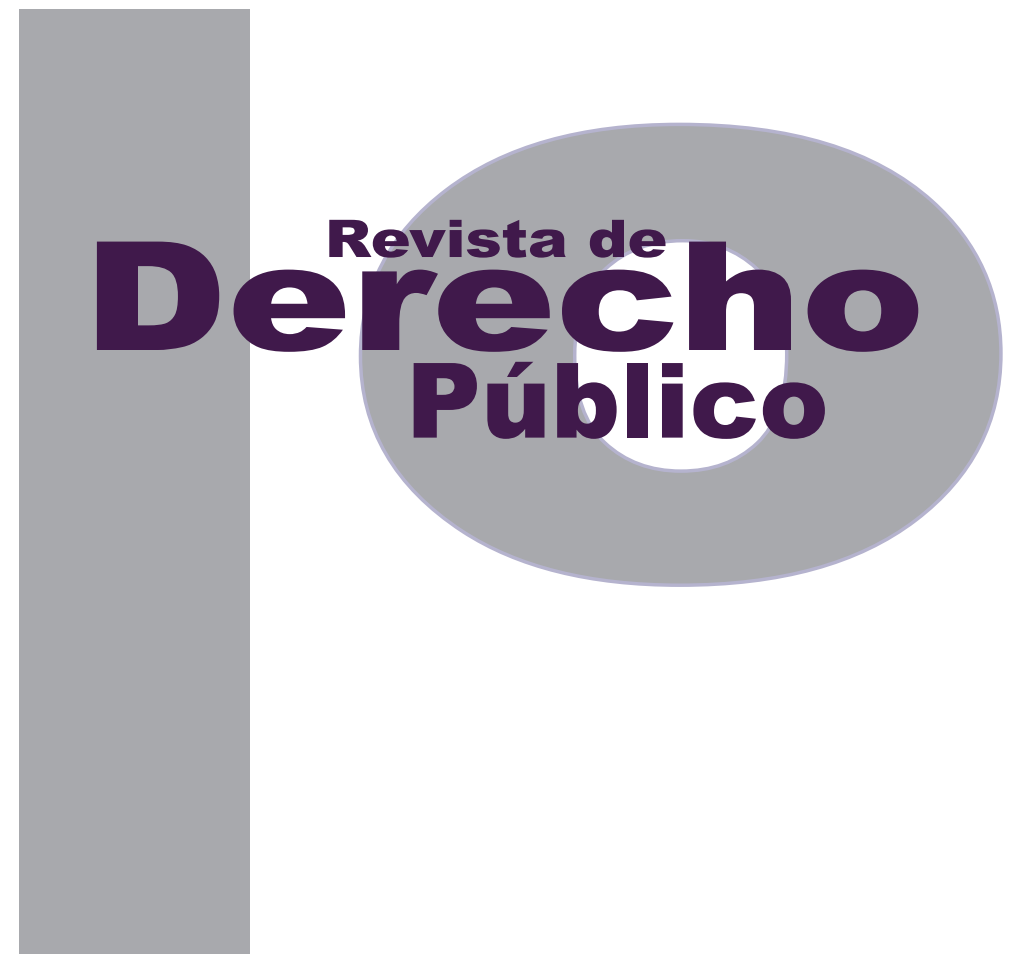

\title{
LAS MESAS DE PARTICIPACIÓN DE VÍCTIMAS: ¿UNA FRUSTRACIÓN MÁS O UN MECANISMO DE TRANSFORMACIÓN SOCIAL?*
}

JULIÁN MARTín BERRÍO**

Universidad de los Andes

Facultad de Derecho

Revista de Derecho Público N. ${ }^{\circ} 31$

Julio - Diciembre de 2013. ISSN 1909-7778 


\title{
Las mesas de participación de víctimas: ¿Una frustración más o un mecanismo de transformación social?*
}

\author{
Julián Martín Berrío**
}

ABSTRACT

\begin{abstract}
RESUMEN
En Colombia, los programas dirigidos a promover la participación de víctimas en el diseño y la veeduría de políticas de asistencia, atención y reparación cobraron especial relevancia a partir de las órdenes de la Corte Constitucional en materia de atención a población desplazada (sentencia T-025 de 2004 y autos de seguimiento), para más tarde convertirse en uno de los ejes fundamentales de la Ley de reparación integral a víctimas del conflicto armado (Ley 1448 de 2011). En esta última Ley, concretamente, se diseñó un mecanismo de participación complejo que, además de ser costoso para el Estado, no ha sido usado para la promulgación de las normas que reglamentan su puesta en marcha. ¿Qué pasó con las mesas de participación de
\end{abstract}

A useful example to analyze the potential and difficulties of victims participation in the development of peace building policies that are efficient is the 1448 Act of 2011 (commonly known in Colombia as "Victims Law"). There is a mechanism involving design complex, besides being costly for the state, has not been used for the promulgation of rules regulating the implementation of the law What happened to the tables? What are the weaknesses of the shareholding system designed by Law 1448 of 2011 and what its potential to become a participatory system that ensures the "empowerment" of the victims? These would be the questions that aspire answer this letter. The article argues that new participation tables, duly empowered, can generate positive

Cómo citar este artículo: Berrío, J. M. (Diciembre, 2013). Las mesas de participación de víctimas: ¿una frustración más o un mecanismo de transformación social? Revista de Derecho Público, 31.

Abogado de la Universidad de los Andes con Maestría en Ciencias Políticas de la misma Universidad. Profesor de planta de la Universidad Católica de Colombia. Correos: julianmartinberrio@gmail.com, jm.berrio584@uniandes.edu.co 
víctimas de la Ley 1448? ¿Qué podemos aprender de la dificultad para instalar las mesas, y qué nos dice esta dificultad de los espacios existentes para la participación de las víctimas? Estas son las preguntas que aspiro responder en el presente escrito. El artículo sostiene que las nuevas mesas de participación pueden generar procesos positivos de transformación de la sociedad colombiana en el posconflicto armado. Pero también advierte que estas pueden ser una frustración más para las organizaciones de víctimas y para el gobierno pues persisten problemas profundos en la concepción del mecanismo de participación diseñado en la Ley 1448. De esta forma, este texto se inserta en la discusión sobre los mecanismos de participación para la construcción de políticas de atención y reparación y para el fortalecimiento político de las organizaciones de víctimas.

Palabras ClaVe: mesas de participación, participación ciudadana, gobernanza, empoderamiento, sociedad civil, organizaciones de víctimas, protocolo de participación. transformation processes Colombian society in post-conflict. But it also warns that they may be one more frustration for victims' organizations and the government because deep problems persist in the concept of sharing mechanism designed in the 1448 Act. Thus, the item is inserted into the discussion about the real utility of participation mechanisms for building and repairing care policies and political empowerment of victims' organizations.

KEY WORDS: participation, governance, empowerment, civil society organizations, victims, participation protocol. 


\section{SUMARIO}

Introducción - I. LOS PROBLEMAS DE LA “PARTICIPACIÓN" EN EL SISTEMA DE PARTICIPACIÓN POR MESAS - A. El problema de los tiempos en la Ley 1448 - B. El problema de la debilidad de la participación de los representantes en los escenarios claves de decisión - C. El problema de la debilidad de las instituciones para la participación en lo local - II. EL POTENCIAL TRANSFORMADOR DE LA PARTICIPACIÓN POR MESAS - III. CONCLUSIONES - Bibliografía. 
Introducción

"Con el respeto que ustedes se merecen, yo hago unas preguntas: ¿para qué estamos acá compañeros?, ¿de cuál participación de las víctimas estamos hablando si la metodología para la discusión del esquema de participación de la Ley 1448 no ha sido concertada con nosotros?, ¿cuál participación de las víctimas si los elementos fundamentales de los planes de asistencia y reparación a las víctimas ya han sido decididos por el Gobierno Nacional sin contar con nuestras inquietudes o propuestas?"...

Es miércoles 24 de octubre de 2012 y así empieza una de las intervenciones de los representantes de las víctimas convocados a la instalación del "espacio transitorio de participación". Quien habla es Tania Bohórquez, líder representante de víctimas del departamento de Sucre. Su protesta se refiere al sistema creado por la Ley de Víctimas, y por sus decretos reglamentarios, para permitir la participación de las organizaciones de víctimas en el diseño, implementación y evaluación de las políticas con las que se pondrá en funcionamiento la Ley.

El día de la protesta de Tania frente a los demás representantes de víctimas y a los funcionarios de la Unidad de Víctimas habían pasado, exactamente, 500 días desde que el presidente Juan Manuel Santos sancionó, el 10 de junio de 2011, la Ley de Víctimas y Restitución de Tierras. Durante este periodo, el Gobierno Nacional promulgó decretos reglamentarios y documentos de política (Conpes) en los que se desarrollaban los programas de asistencia, atención y reparación que ordena la Ley (con fases, objetivos y cronogramas de implementación). Sin embargo, la participación de las víctimas en estos decretos fue limitada, en parte porque aún no estaba instalado el mecanismo que la misma Ley 1448 dispuso para ello: las mesas de participación. ${ }^{1}$

No en vano, a finales del mes de octubre de 2012 apenas se empezaba a discutir con las víctimas, en un espacio transitorio, la elección de los representantes ante los subcomités técnicos ${ }^{2}$ y los detalles para la construcción del protocolo de participación (que es el texto definitivo en el que se reglamenta el esquema de mesas de participación referido).

Este artículo da cuenta del proceso que va entre la adopción de la Ley de Víctimas y la instalación del espacio transitorio con representantes encargados de proponer y consultar un protocolo de participación, y con base en la experiencia anterior con mesas similares para la población desplazada, argumenta que las nuevas mesas pueden generar procesos positivos de transformación de la sociedad colombiana y en la relación entre la sociedad civil y las instituciones. Pero también advierte que las mesas pueden ser una frustración más tanto para las organiza-

1 Entrevista a Angeliza Zamora, investigadora del Área de Incidencia en Políticas Públicas de la Fundación Social, y funcionaria pública de la Unidad Administrativa Especial para la Atención y Reparación Integral a las Víctimas. Bogotá, enero 12 de 2012. Entrevista a Alejandra Saffon, funcionaria de la Dirección de Justicia Transicional del Ministerio de Justicia y del Derecho. Bogotá, enero 25 de 2012.

2 Los subcomités técnicos son grupos de trabajo interinstitucional encargados del diseño de la política pública de prevención, asistencia, atención y reparación integral a las víctimas. Estos presentan insumos para que el Comité Ejecutivo para la Atención y Reparación a las Víctimas tome decisiones sobre los planes, programas y estrategias de atención, asistencia y reparación a las víctimas. Decreto 4800 de 2011, art. 238. 
ciones de víctimas como para el gobierno en su búsqueda de mayor legitimidad y eficiencia en el proceso de transición.

El 24 de octubre de 2012, sin embargo, en el "espacio transitorio" había muchos caminos abiertos para el proceso de participación de las víctimas. La protesta de Tania Bohórquez, secundada por varios líderes de víctimas que asistieron a la instalación, era apenas una advertencia. Representantes de diversas regiones del país (de origen campesino, indígena y afrocolombiano) se quejaron de la ausencia de garantías para la participación efectiva en el diseño e implementación de las políticas de asistencia, atención y reparación. Por ejemplo, algunos líderes manifestaron su inconformidad por no haber sido tenidos en cuenta para la expedición del Plan Nacional de Atención y Reparación Integral a las Víctimas ${ }^{3}$ y otros afirmaron no tener claridad sobre la forma en que se articularían las mesas de participación de población desplazada y las mesas de participación contempladas en la Ley 1448 de $2011 .^{4}$ En este punto, en particular, surgieron algunas tensiones entre los antiguos y los nuevos líderes, pues los representantes de población desplazada manifestaron sentirse subvalorados e ignorados en la construcción del nuevo mecanismo de participación. Incluso, algunas voces plantearon

3 Adoptado mediante el Decreto 1725 de 2012. Su objetivo fundamental es establecer los mecanismos necesarios para la implementación de todas las medidas de atención, asistencia y reparación integral de que trata la Ley 1448 de 2011

$4 \quad$ Intervención de Leonel Uribe Hernández, líder de víctimas del departamento de Boyacá. Bogotá, octubre 24 de 2012. Entrevista a Edwin Mendoza, líder de víctimas del departamento de Huila, Bogotá, octubre 24 de 2012. Intervención de Ernestina Martínez Caballero, líder de víctimas del departamento de César. Bogotá, octubre 24 de 2012. la cancelación del "espacio transitorio" pues consideraban que no existía suficiente compromiso del Estado ni claridad sobre la forma en que habían sido escogidos los voceros que allí participaban. $^{5}$

En la misma vía, varios de los representantes de víctimas presentes cuestionaron la idoneidad del sistema de participación adoptado en la Ley 1448, dado que algunos de los instrumentos de política más importantes (por ejemplo, el Decreto reglamentario 4800 de 2011 o el Conpes 3726 de 2012) ya habían sido promulgados por el Gobierno Nacional sin que las víctimas hubiesen podido tramitar sus propuestas, quejas o inquietudes a través de las mesas. En este sentido, algunos representantes evidenciaron los problemas de coordinación, mientras distintos líderes desaprobaron el mecanismo dispuesto por el Gobierno para la elección de los representantes de las víctimas ante los subcomités técnicos encargados de orientar los planes y programas que se desprenden de la Ley $1448 .{ }^{6}$

Este ambiente de inconformidad y desconcierto que caracterizó la instalación del "espacio transitorio", sin embargo, contrastaba con el optimismo reflejado por algunos actores de la sociedad civil y el Gobierno sobre la participación de las víctimas en el proceso. Solo como ejemplo cabe recordar las palabras de Paula Gaviria -directora de la Unidad de Atención y Reparación Integral a las Víctimas, quien insistió varias ve-

5 Intervención de Ángel María, líder de víctimas del departamento de Arauca. Bogotá, octubre 24 de 2012. Entrevista a Alfonso Castillo, líder de víctimas de crímenes de Estado. Bogotá, octubre 24 de 2012.

6 Ibíd. Nota 3 
ces en que el sistema de participación diseñado en la Ley 1448 sí es una herramienta útil para que las víctimas intervengan de forma activa y eficiente en la construcción y ejecución de los programas de asistencia, atención y reparación: “[...] toda la política se estructura a partir de la participación efectiva de las víctimas. Todas las instancias de decisión de la ley cuentan con representantes de víctimas y el Protocolo de Participación Efectiva buscará garantizar la incidencia de la sociedad civil en el diseño y la veeduría de la política".7

Aun cuando para finales del año 2012 ni siquiera existía un documento acordado de "protocolo de participación", y a pesar de que el sistema de mesas de participación no pudo ser usado como mecanismo de interlocución de las víctimas en el diseño del Decreto 4800, el Plan de Atención y Reparación Integral y el Conpes 3726, representantes del Gobierno sostuvieron que las mesas de participación sí les permitirían a las víctimas intervenir (con voz y voto) y hacer propuestas concretas en los comités (de orden nacional y departamental) en los que se decide el contenido de las políticas de asistencia, atención y reparación. ${ }^{8}$

Con este telón de fondo, el propósito de este texto es explorar el impacto real que tiene la implementación de un "nuevo" modelo de participación para víctimas siguiendo las siguientes preguntas centrales: ¿qué pasó con las mesas

7 Aparte del discurso de Paula Gaviria, directora de la Unidad Administrativa Especial para la Atención y Reparación Integral a las Víctimas. Bogotá, octubre 25 de 2012.

8 Entrevista a Angeliza Zamora y a Alejandra Saffon. Ibíd., nota 2. de participación de la Ley 1448?, ¿qué podemos aprender de la dificultad para instalar las mesas, y qué nos dice esta dificultad de los espacios existentes para la participación de las víctimas? La propuesta de análisis que aquí se presenta tiene dos aspectos. Por un lado, avanza en identificar los vacíos del sistema de participación propuesto en la Ley 1448 de 2011 y, por el otro, abre el camino para debatir sobre la idoneidad de este sistema de participación como un mecanismo eficaz para la interlocución entre las víctimas y las instituciones encargadas de atenderlas.

Para responder a las preguntas planteadas, el texto se encuentra dividido en tres partes. En la primera (I) se señalan, por un lado, los problemas que impidieron que el sistema garantizara una participación efectiva de las víctimas en la construcción de las políticas contenidas en el Decreto 4800 de 2011, el Plan Nacional de Atención y Reparación Integral y el Conpes 3726 de 2012; y por el otro, las razones por las que el sistema de participación diseñado en la Ley 1448 de 2011 (aun funcionando idealmente) no garantiza la incidencia de las víctimas en los escenarios claves de decisión sobre el diseño y la implementación de las políticas. Igualmente, se muestran algunos problemas derivados de la debilidad de algunas instituciones del Estado en el nivel local (municipios y gobernaciones).

En la segunda parte (II) se destacan algunos aspectos que resaltan las potencialidades del sistema de participación diseñado en la Ley de Víctimas. En concreto, se explica qué tipo de ajustes se pueden hacer para que el sistema 
de participación traslade a las víctimas la capacidad de tomar decisiones autónomas sobre el uso de algunos recursos destinados a la reparación, y sobre el contenido específico de los programas con los que se les atiende o repara. Por último, en la tercera parte (III), se ofrecen algunas conclusiones generales.

\section{LOS PROBLEMAS DE LA “PARTICIPACIÓN" EN EL SISTEMA DE PARTICIPACIÓN POR MESAS}

A lo largo de los debates del Proyecto de Ley de Víctimas (pLV) en el Congreso, distintos senadores mencionaron la relevancia de considerar mecanismos que garantizaran a las víctimas y a las organizaciones que las representan la posibilidad de intervenir (haciendo propuestas $\mathrm{u}$ objetando contenidos) en el diseño, implementación y ejecución de las políticas de reparación. ${ }^{9}$ No obstante, fue solo en el marco de la discusión del pLv en la Comisión Primera del Senado que se debatieron propuestas concretas de cambio al texto, y se definieron las modificaciones que se mantendrían hasta la votación y aprobación del Informe de Conciliación por parte de la Cámara de Representantes y el Senado de la República.

El senador Jorge Londoño (del Partido Verde) intervino en la sesión del 23 de marzo de 2011 para presentar una proposición con el objetivo

9 Las diferentes menciones de los senadores a este tema pueden consultarse en (Fundación Social et al., 2011). Allí se refieren las posiciones del senador liberal Juan Fernando Cristo y del senador del Polo Democrático Alternativo (hoy en la Alianza Progresista) Luis Carlos Avellaneda, quienes junto con el senador Jorge Eduardo Londoño fueron los que más insistieron en esta necesidad. de corregir y ampliar las garantías que hasta ese momento ofrecía el capítulo de participación ciudadana del plv. Destacando el apoyo brindado por el área de incidencia en políticas públicas de la Fundación Social para la elaboración de la propuesta, Londoño explicó el alcance de sus proposiciones para la creación de un sistema de mesas del orden municipal, departamental y nacional que aseguraran la participación y veeduría de las víctimas ante todas las instancias de decisión e implementación contempladas en el pLV (Fundación Social, Organización Internacional para la Migraciones y USAID, 2011, p. 4). Concretamente, el nuevo artículo de participación propuesto por Londoño ordenaba al Gobierno Nacional que en el término de seis (6) meses conformara unas mesas de víctimas en el orden nacional, departamental y municipal que facilitaran la participación de estas, especialmente de las mujeres, niñas, niños, adolescentes y adultos mayores. Esas mesas deberían reflejar las agendas de sus miembros y les permitirían a las víctimas participar en ejercicios de rendición de cuentas de las entidades responsables de la ejecución de la Ley, y adelantar procesos de veeduría ciudadana sin perjuicio del control social que otras organizaciones al margen de este espacio pudieran hacer (Fundación Social et al., 2011, p. 4).

La proposición de Londoño que cambiaba la redacción del artículo 193 Proyecto Comisión Senado (P. C. S.) fue votada y aprobada mayoritariamente por la Comisión Primera del Senado en la sesión del 11 de abril de 2011, como parte de un bloque de artículos con proposiciones que estaban acordadas y avaladas por los ponentes 
(Fundación Social et al., 2011c, pp. 3-4). Los artículos 192 y 194 P. C. S. que completaban el capítulo de participación ciudadana del PLV fueron aprobados unánimemente por la Comisión, como parte de un bloque de 85 artículos sin proposiciones, en la sesión del 5 de abril de 2011 (Fundación Social et al., 2011e, pp. 1-2). ${ }^{10}$

A pesar de las buenas intenciones, el sistema de participación desarrollado en la Ley 1448 de 2011 presenta una serie de problemas de diseño. El primero tiene que ver con los tiempos: montar el sistema requería un tiempo de por lo menos un año; sin embargo, la Ley ordenaba que se adoptaran las políticas claves, así como los decretos reglamentarios en un tiempo menor al necesario para el montaje y operación de las mesas de participación. Por lo tanto, como denunciaba Tania Bohórquez, en octubre de 2012,

10 Para la ponencia del PLV, presentada en el debate de la Plenaria del Senado, se hicieron algunas correcciones de forma al texto de los artículos del capítulo de participación ciudadana y se le añadió un parágrafo nuevo al artículo 193 P. C. S. (que pasó a ser el artículo 194 del texto P. P. S. como consecuencia de la inclusión de un artículo nuevo), ordenando a la Unidad Administrativa Especial para la Atención y Reparación Integral a las Víctimas establecer el procedimiento para la integración de los mecanismos de participación de la población desplazada en la institucionalidad encargada del diseño, la implementación y la ejecución de los planes y programas de reparación. En concreto, las propuestas las hizo el senador Jorge Eduardo Londoño, del Partido Verde, en el marco de los debates en la Comisión Primera del Senado; en una de sus intervenciones advirtió que establecer un asiento para la representación de las víctimas en el Consejo Directivo de la Unidad Administrativa Especial para la Atención y Reparación Integral a las víctimas, que está conformado por doce miembros, no era una garantía de participación suficiente que les permitiera incidir directamente en la definición de los planes y programas con los que el Estado buscaría atenderles. En la misma vía, Londoño criticó la propuesta de participación ciudadana que estaba incluida en la ponencia para primer debate en esa Comisión, porque carecía de indicadores o criterios precisos que permitieran identificar cuál era el alcance de la participación de las víctimas dentro de las instancias de decisión que se contemplaban en el PLV, concretamente, porque no definía expresamente si la opinión de los representantes de las víctimas tenía, por ejemplo, un poder de veto frente a las decisiones que tomaría la institución encargada de implementar las medidas de reparación (Fundación Social, 2011i, p. 7). buena parte de estos diseños y políticas se hicieron sin la participación institucionalizada que preveía la Ley 1448. Así sucedió, como lo explico en la siguiente sección, con el Decreto 4800 de 2011, reglamentario de la Ley 1448, así como con el Plan Nacional de Atención y Reparación Integral y el Conpes 3726 de 2012. Esta debilidad, como lo muestra la anécdota con la que inicio este capítulo, tiene un fuerte impacto negativo sobre la legitimidad de las políticas y la confianza de los líderes en el gobierno.

Además de la falta de participación institucionalizada en la adopción de estos documentos centrales para la implementación de la Ley, un segundo problema importante del esquema de mesas de participación de víctimas es que su diseño actual perpetúa las dificultades que tuvieron las mesas de fortalecimiento de organizaciones de población desplazada (en adelante mesas de OPD). En primer lugar, tienen una débil presencia y función en los espacios de toma de decisiones. Como se explicará en detalle más adelante, los representantes de las mesas que participan en aquellos comités en los que se toman decisiones relevantes sobre el contenido de las políticas de reparación no cuentan con una delegación que les garantice poder influir de manera decisiva al momento de votar por la adopción de una u otra alternativa de política. En segundo lugar, también como en las mesas de OPD, la participación de las víctimas depende de una incipiente institucionalidad a nivel territorial $^{11}$ y de un débil mecanismo de coordi-

11 La debilidad de las instituciones responsables de implementar políticas de atención y asistencia a desplazados ha sido, de acuerdo con la Corte Constitucional, una de las razones por las que se perpetúa 
nación con el nivel nacional. Esta fragilidad se predica tanto de las instituciones públicas como de las mismas organizaciones que pretenden representar los intereses de las víctimas. Tanto las instituciones públicas de nivel local como las organizaciones tienen liderazgos muy heterogéneos y a menudo son propicios para la cooptación por parte de intereses individuales y privados. Es previsible que estas debilidades tengan un impacto negativo en la legitimidad tanto del sistema de participación como de la interlocución con el gobierno, e incluso en la posibilidad de recibir una retroalimentación efectiva de las organizaciones sobre las reglas y políticas que se adopten para esta población.

\section{A. El problema de los tiempos en la Ley 1448}

Los lineamientos sobre los espacios de participación en los planes y los mismos planes de atención, asistencia y reparación con los que el Estado piensa atender a las víctimas quedaron dispersos en la Ley 1448, sus decretos reglamentarios y algunos documentos de política pública (como el Conpes 3726 de 2012). No obstante, aunque la cláusula normativa general dice que las víctimas "participarán”, lo cierto es que esa participación no se unificó con un criterio general bajo el nuevo sistema de participación por mesas. Esto se debió, principalmente, a la falta de coherencia en los tiempos para el diseño de las políticas y los tiempos para montar el sistema de participación.

La Ley 1448 de 2011 señaló distintos plazos para el diseño e implementación de las medidas de asistencia, atención y reparación, y para la conformación de las mesas de participación en el nivel municipal y departamental. Como se puede ver en el cuadro 1, el sistema de participación debía estar operando en diciembre de 2011. Sin embargo, para esa fecha solo se habían definido los lineamientos para la conformación de las mesas (Decreto 4800) y aún estaba pendiente la construcción de protocolo de participación (que es la herramienta jurídica en la que se fijan los procedimientos y trámites concretos para la formación y el funcionamiento de las mesas de participación de víctimas).

el estado de cosas inconstitucional del desplazamiento forzado. Este contexto de debilidad institucional en el que se adelantan los programas de atención a víctimas fue recordado por la Corte en el Auto 219 de 2011 (M. P.: Luis Ernesto Vargas) en el que sostuvo: "recuerda la Corte que uno de los aspectos más importantes que contribuye a la persistencia del estado de cosas inconstitucional en materia de desplazamiento forzado es la precaria capacidad institucional del Estado para asegurar el goce efectivo de los derechos de esta población y que de acuerdo con la herramienta de certificación del desempeño de las entidades u organismos del Sistema Nacional de Atención Integral a la Población Desplazada, los resultados en términos de corrección de las falencias identificadas y de diagnóstico frente a la dimensión del problema que se debe resolver han sido tan reducidos, que se está ante el eventual incumplimiento de lo ordenado". 
Cuadro 1:

Medidas, plazos y responsables

MEDIDA

PLAZO

RESPONSABLE

Reglamentación de la indemnización administrativa. Incluye la reglamentación del procedimiento, los rangos de montos, las tablas de valorización y la definición de los criterios con los cuales será entregada la indemnización (Ley 1448, art. 132).

Creación del Programa de Rehabilitación. Incluye las medidas individuales y colectivas que les permiten a las víctimas desempeñarse en su entorno familiar, cultural, laboral y social, y ejercer sus derechos y libertades básicas de manera individual y colectiva (Ley 1448, art. 136).

Creación del Programa de Atención Psicosocial y Salud Integral para las Víctimas. Incluye la reglamentación del tipo de apoyo que en materia psicosocial y en salud se les prestará a las víctimas (Ley 1448, art. 137).

Creación del Programa de Reparación Colectiva. Incluye la reglamentación sobre el tipo de medidas de reparación que procederán de acuerdo con los daños ocasionados por las violaciones de derechos humanos, teniendo en cuenta el impacto colectivo de la violación de los derechos individuales (Ley 1448, art. 151).

Creación del Plan Nacional de Atención y Reparación Integral a las Víctimas. Incluye la reglamentación sobre todas las medidas de atención, asistencia y reparación, junto con el plan de ejecución de metas, presupuesto y mecanismos de veeduría y seguimiento.

Diseño e implementación de programas de prevención, asistencia, atención y reparación a cargo de las entidades territoriales (de acuerdo con los lineamientos del Plan Nacional de Atención y Reparación Integral.

Creación y conformación del sistema de participación por mesas. Incluye la reglamentación de todos los mecanismos de participación con los que cuentan las organizaciones de víctimas y las organizaciones defensoras de los derechos de las víctimas para incidir en el diseño e implementación de las medidas.

\section{- Gobierno Nacional. No se establece ningún \\ 6 meses mecanismo de participación específico para \\ (dic. 2011) que las víctimas puedan intervenir en la reglamentación.}

1. Gobierno Nacional. No se establece ningún

6 meses (dic. 2011)

-

6 meses

(dic. 2011)

6 meses

(dic. 2011)

1 año

(jun. 2012)

\section{e} (2)

1 año

(jun. 2012)

5. Entidades territoriales.

6 meses

(dic. 2011)
3. Gobierno Nacional a través de la Unidad Administrativa Especial para la Atención y Reparación Integral de las Víctimas. No se establece ningún mecanismo de participación específico para que las víctimas puedan intervenir en la reglamentación.

4. Gobierno Nacional. No se establece ningún mecanismo de participación específico para que las víctimas puedan intervenir en la reglamentación. 
De este modo, el Decreto 4800, que es la norma en la que se reglamentan todos aquellos programas que debían estar diseñados para diciembre de 2011, no pudo ser sometido a la consideración de las víctimas a través del esquema de participación por mesas. En su defecto se cumplió un "proceso de consulta" a través de talleres regionales ${ }^{12}$ que, si bien representan un avance en la interlocución entre la sociedad civil y el Estado, su metodología no permitió la participación activa de las víctimas en el diseño de los planes y programas que debían estar listos para diciembre de 2011, al menos, por dos razones principales: primera, a pesar de que el Gobierno Nacional abrió distintos canales de comunicación para recibir comentarios sobre las propuestas de reglamentación de los planes y programas, los textos no se enviaron con la anterioridad suficiente a las organizaciones de víctimas para que estas pudieran estudiarlas y

12 Se llevaron a cabo 7 talleres regionales en el segundo semestre de 2011. En ellos participaron personas residenciadas en los departamentos que se indican en cada uno, así: 1er taller: Manizales (5 a 7 de octubre): Tolima, Quindío, Huila, Risaralda y Caldas. $2^{\text {do }}$ taller:

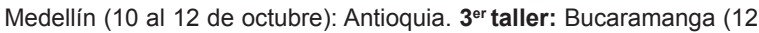
al 14 de octubre): Arauca, Norte de Santander y Santander. $4^{\text {to }}$ taller: Santa Marta (17 al 19 de octubre): La Guajira, Magdalena, Cesar, Sucre, Bolívar, Atlántico y Córdoba. $5^{\text {to }}$ taller: Cali (19 y 21 de octubre): Nariño, Valle, Cauca, Putumayo y Chocó. $6^{\text {to }}$ taller: Amazonía y Orinoquía (24 al 26 de octubre): Amazonas, Caquetá, Meta, Casanare, Guaviare, Vichada, Guainía, Vaupés y Boyacá. $7^{\mathrm{mo}}$ taller: Bogotá $\left(1^{\circ} \mathrm{al}\right.$ 3 de noviembre): Cundinamarca y el Distrito Capital. En cada taller se abrieron dos espacios de discusión: uno para víctimas, donde participó la población desplazada, y otro para instituciones. Con el apoyo de la cooperación internacional (FUPAD, USAID y la GIZ) se adoptó una metodología, se cubrió la participación de las personas y la organización logística de los eventos. En total, a los talleres asistieron 678 víctimas y 456 representantes de instituciones y autoridades locales. El énfasis metodológico de los talleres consistió en una experiencia de trabajo personal y colectivo, activo y participativo, que contemplaba el aporte de cada una (o) de las y los integrantes con preguntas, apreciaciones, sugerencias y comentarios tanto sobre la Ley como respecto de los documentos sometidos a retroalimentación, así como preguntas, sugerencias y conclusiones sobre todos los temas reglamentados. Los comentarios se recogieron en un aplicativo por medio del cual se sistematizaba la información. El número de comentarios recogidos en los talleres fue de 7.229. (Subcomité de Participación, 2011d). formarse una opinión antes de que se abriera el espacio de "consulta", por tanto, los intervinientes en los talleres los conocían el mismo día de la socialización o con muy poco tiempo de antelación; segunda, en el transcurso de los talleres no se siguió una metodología que permitiera ir más allá de la simple recolección de sugerencias. ${ }^{13}$

En este sentido, si bien los talleres les permitieron a algunas de las organizaciones de víctimas y organizaciones defensoras de los derechos de las víctimas (ODDV) presentar comentarios y sugerencias concretas, no es posible cuantificar el impacto directo de estas sugerencias en el texto final de la reglamentación. Dadas las limitaciones institucionales para tramitar los comentarios, y la cantidad y la diversidad de las sugerencias recibidas (que iban desde correcciones ortográficas hasta nuevos artículos), estos espacios se redujeron a validar el requisito formal de participación de las víctimas respecto a propuestas estatales prefijadas. ${ }^{14} \mathrm{Sin}$ desconocer un esfuerzo institucional significativo para recoger una cantidad considerable de comentarios y sugerencias, este simple hecho no significa que los constructores de la política

13 Entrevista a Alejandra Saffon, ibíd., nota 2. (Subcomité de Participación, 2011d).

14 Como lo muestra el Informe metodológico de la implementación de la Ley 1448 y las primeras actas de reuniones del Subcomité de Participación, las sugerencias de fondo al articulado de los decretos reglamentarios de la Ley de Víctimas que presentaron los participantes se recogieron y después se emitió un acta integral con respuestas generales que explicaban, en la mayoría de los casos, por qué los artículos se mantenían de la misma forma (o muy similares) a como fueron presentados antes de la intervención de las víctimas en los taIleres. Sobre este punto particular se puede revisar el Acta No. 3 del 15 de noviembre de 2011, del Subcomité de participación de la Ley de Víctimas (Subcomité de Participación, 2011c). 
tomaran seriamente en consideración las propuestas recibidas.

Un análisis de la metodología de participación usada en ausencia de las mesas revela que el Estado concentró sus esfuerzos en los aspectos formales de los talleres (provisión de apoyo básico: medios de transporte, gastos de viaje, legalización de gastos, estadía y logística de las reuniones) y descuidó la manera como las propuestas de las víctimas podían ser tenidas en cuenta en la formulación de los instrumentos de planeación y coordinación de algunas de las políticas de atención, asistencia y reparación de las víctimas del conflicto armado. ${ }^{15}$

Igual ocurrió con el Plan Nacional de Atención y Reparación Integral a las Víctimas, que incluye la reglamentación de todas las medidas de atención, asistencia y reparación. Para el momento en que debía estar listo (junio de 2012) todavía no se había elaborado (y mucho menos implementado) el protocolo de participación, por lo tanto, el Gobierno Nacional debió someterlo a consideración de las víctimas a través de talleres de socialización realizados en distintas regiones, bajo la misma lógica de los del Decreto 4800 de 2011. Como lo señalan algunos líderes intervinientes en este proceso, los talleres no garantizaron la participación en el diseño de los programas del Plan, simplemente se limitaron a la recolección de sugerencias que en la mayoría de las casos no eran pertinentes, entre otras, porque las víctimas y sus organizaciones no con-

15 Entrevista a Edwin Mendoza y a Ernestina Martínez Caballero, ibíd., nota 5. Entrevista a Alfonso Castillo, ibíd., nota 6. taron con un tiempo razonable para estudiar y evaluar la propuesta de Plan con la que llegaba el Gobierno. ${ }^{16}$ En contraste con esta situación, las víctimas insistieron en que una verdadera participación les debería garantizar poder de veto frente a algunas propuestas o apropiación de recursos para el manejo autónomo de las organizaciones o los representantes de víctimas. ${ }^{17}$ Igualmente, señalaron que una participación genuina debería incorporar a las organizaciones y los representantes como actores del proceso de implementación, es decir, que para la puesta en marcha de algunos programas específicos se contraten víctimas u organizaciones de víctimas con experiencia, por ejemplo, en trabajo con enfoque de género o apoyo psicosocial. ${ }^{18}$

Por su parte, el documento Conpes 3726 de 2012 (que integra los lineamientos, el plan de ejecución de metas, el presupuesto y el mecanismo de seguimiento para el Plan Nacional de Atención y Reparación Integral de Víctimas) tampoco fue sometido a consideración de las víctimas. Si bien se puede argumentar que este tipo de documentos de política no necesariamente deben ser discutidos con los representantes de las víctimas, lo cierto es que siendo un documento central en el desarrollo y la ejecución de los planes ordenados en la Ley 1448, al menos re-

16 Entrevista a Edwin Mendoza, ibíd., nota 5.

17 Entrevista a Ernestina Martínez Caballero, ibíd., nota 5 y a Alfonso Castillo, íbíd., nota 6.

18 Entrevista a Leonel Uribe Hernández, ibíd., nota 5. De acuerdo con Uribe, "que las víctimas trabajen con las víctimas propicia un proceso de mutuo reconocimiento que puede contribuir a la rehabilitación del daño causado y a la pacificación (en la medida en que se reconocen la dificultades de otros)". 
quería algún tipo de socialización que les permitiera (en un plazo determinado) hacer algún tipo de comentarios o formular alguna sugerencia. Naturalmente, los comentarios y sugerencias nunca llegaron y el documento se expidió con rutas de atención y reparación integral pero sin que se discutiera con las víctimas la idoneidad de esas estrategias de acuerdo, entre otros, con las condiciones de las instituciones públicas de los diversos departamentos y municipios.

Algunas personas podrían aducir que el diseño de los tiempos fue adecuado, teniendo en cuenta que convocar a las víctimas para discutir todos los documentos en los que se desarrollan políticas de asistencia, atención y reparación (por ejemplo, el Conpes 3726 de 2012) atrasaría los procesos y con ello perderían todos: las víctimas porque la implementación de los planes se demoraría, y el gobierno por los problemas derivados de la inejecución. La pregunta subyacente es si la participación de las víctimas garantiza o no que las políticas adoptadas sean más adecuadas a las circunstancias "en el terreno" y obedezcan a políticas más legítimas. El tema de la legitimidad es especialmente problemático, ya que "las víctimas" son un grupo poblacional heterogéneo en el que confluyen personas con distintos intereses y prioridades, de distintas regiones y con experiencias muy diversas.

Sin embargo, frente a este tipo de posiciones puede decirse lo siguiente: aun cuando es cierto que las víctimas son un grupo poblacional heterogéneo (en el que hay quienes desconfían entre sí, algunos buscan imponer sus intereses a toda costa y otros no consideran posible la adopción de ciertas decisiones por consenso), también es cierto que "la sensación de engaño" que genera en las víctimas el hecho de que les prometan participar y luego "les salgan con nada" tiene costos altos en legitimidad que obstaculizan la implementación eficaz de las políticas. Como se pudo evidenciar en las intervenciones de distintos líderes durante la instalación del espacio transitorio, esa "sensación de engaño" produce desconfianza en las instituciones, y esa desconfianza entorpece la interlocución entre el gobierno y las víctimas.

La falta de fluidez en la interlocución tiene, al menos, dos consecuencias evidentes: primera, genera divisiones políticas entre las víctimas en razón de que algunos líderes defienden el proceso adelantado por el Gobierno y piden seguir adelante, mientras otros buscan reivindicarse e invitan a "no marchar al ritmo" de las órdenes de las entidades públicas; esto, como es obvio, complejiza la movilización de las víctimas como sujeto político y la consolidación de liderazgos perdurables; segunda, como lo expresó Hernán Rocha (líder de víctimas representante de la organización Corporación Sociedad Activa), hace que los líderes se cuestionen sobre la utilidad del rol que desempeñan (pues algunos manifiestan sentir que nada de lo que digan o hagan va a verse reflejado en la implementación de las políticas). Dudar de la utilidad de su rol da al traste con uno de los incentivos fundamentales de la participación: creer que se participa con algún objetivo específico y con poder real de incidencia.

Ahora bien, además de que el sistema de participación diseñado en la Ley 1448 de 2011 no 
fue utilizado para la definición de los planes de atención y reparación, como se verá en la siguiente sección, este tampoco garantiza la incidencia de las víctimas en la toma de decisiones relevantes. Veamos:

\section{B. El problema de la debilidad de la participación de los representantes en los escenarios claves de decisión}

El sistema de participación adoptado en la Ley 1448 de 2011 y sus decretos reglamentarios se encuentra dividido en dos escenarios principales. Por un lado, están las mesas de participación, que son espacios de trabajo dispuestos para que las organizaciones de víctimas y las oDDV discutan, interactúen, propongan políticas y ejerzan veeduría sobre el cumplimiento de la Ley. ${ }^{19}$ Su orientación, estructura interna y funcionamiento, salvo por algunos lineamientos generales señalados en el protocolo de participación, es decidido autónomamente por las organizaciones inscritas.

Hay mesas de participación en tres niveles: municipal, ${ }^{20}$ departamental ${ }^{21}$ y nacional, y en

19 Decreto 4800 de 2011, art. 264.

20 De acuerdo con el artículo 274, párr. 1 del Decreto 4800 de 2011, en aquellos municipios y distritos con más de un millón de habitantes se podrán conformar espacios de participación locales. A pesar de que el artículo señala que estos espacios subregionales deben ser creados a "instancias de las entidades territoriales municipales y distritales", no queda claro si son las propias organizaciones inscritas en una mesa municipal o las entidades territoriales como la Personería o la Alcaldía las que deciden sobre la conformación o no de espacios locales de participación. Tampoco es claro si estos espacios adicionales tendrían el mismo poder deliberativo y decisorio de las mesas municipales.

21 De acuerdo con el artículo 275, párr. 1 del Decreto 4800 de 2011, en aquellos departamentos con más de sesenta municipios se podrán conformar espacios de participación subregionales. En este caso, como en el de la construcción de "espacios de participación locales", todos podrán intervenir ambos tipos de organizaciones. De acuerdo con la reglamentación del Decreto 4800 y del protocolo, para que una organización pueda intervenir en las mesas departamentales es necesario que pertenezca a una mesa municipal, y para que pueda intervenir en la mesa nacional es necesario que esté inscrita ante alguna mesa departamental. ${ }^{22}$

Las personerías, en el orden municipal, y las defensorías regionales, en el orden departamental, ejercen la secretaría técnica de las mesas de participación ${ }^{23} y$, en consecuencia, tienen función no solo de "garantes de la participación" en la medida en que son responsables de la inscripción de las organizaciones, de la citación y formalidades de las reuniones (preparar la agenda de trabajo, levantar las actas con los asuntos acordados y los compromisos adquiridos en las sesiones, etc.), sino de recibir y tramitar las reclamaciones que hagan las organizaciones, de informar sobre los programas de atención y reparación implementados, de apoyarlas en la elaboración de recomendaciones u observaciones respecto de los planes que se estén ejecutando y de apoyar a las organizaciones de las respectivas mesas en la definición de un plan de trabajo que les permita cumplir con su función de veedoras respecto a la ejecución de la Ley $1448 .^{24}$

no hay claridad sobre quién y cómo se pueden conformar.

22 Decreto 4800 de 2011, art. 264.

23 Decreto 4800 de 2011, art. 287

24 Decreto 4800 de 2011, art. 288 
Por su parte, la Mesa de Participación Nacional se conforma con un vocero elegido por cada una de las mesas departamentales. Como se mencionó anteriormente, para ser parte de esta mesa, las organizaciones cuyos integrantes hayan sido elegidos como voceros deberán estar inscritas ante alguna mesa departamental. ${ }^{25} \mathrm{La}$ secretaría técnica de la Mesa Nacional es ejercida por la Defensoría del Pueblo. ${ }^{26}$
Ahora bien, las mesas de participación en los tres niveles tienen tareas específicas y tareas comunes. Las tareas específicas están ligadas a la elección de determinados representantes y voceros, y las tareas comunes están enunciadas en términos normativos generales y abstractos. El cuadro 2 es útil para ilustrar cuáles funciones son responsabilidad privativa de qué mesas y cuáles son comunes en todos los niveles.

\section{Cuadro 2:}

Mesas de participación: funciones privativas y funciones comunes

\begin{tabular}{|c|c|c|}
\hline MESA & FUNCIONES PRIVATIVAS & FUNCIONES COMUNES \\
\hline $\begin{array}{l}\text { Mesa Municipal de } \\
\text { Participación }\end{array}$ & $\begin{array}{l}\text { - Si se conforma un Comité Territorial de } \\
\text { Justicia Transicional en el respectivo nivel } \\
\text { municipal, esta mesa deberá escoger a } \\
\text { dos representantes de las víctimas ante } \\
\text { esa instancia. }\end{array}$ & $\begin{array}{l}\text { - Servir de escenario propicio } \\
\text { para la discusión, interacción } \\
\text { y proposición de políticas } \\
\text { públicas de atención y repa- } \\
\text { ración. }\end{array}$ \\
\hline $\begin{array}{l}\text { Mesa Departamental } \\
\text { de Participación }\end{array}$ & $\begin{array}{l}\text { - Si se conforma un Comité Territorial de } \\
\text { Jus ticia Transicional en el respectivo } \\
\text { nivel departamental, esta mesa deberá } \\
\text { escoger a dos representantes de las víc- } \\
\text { timas ante esa instancia. }\end{array}$ & $\begin{array}{l}\text { para los ejercicios de ren- } \\
\text { dición de cuentas y veeduría } \\
\text { ciudadana respecto de la } \\
\text { implementación de la Ley } \\
1448 \text { y su normatividad rela- }\end{array}$ \\
\hline $\begin{array}{l}\text { Mesa Nacional de Par- } \\
\text { ticipación }\end{array}$ & $\begin{array}{l}\text { - Elegir a los representantes ante el Con- } \\
\text { sejo Directivo de la Unidad Administra- } \\
\text { tiva Especial de Restitución de Tierras } \\
\text { Despojadas. } \\
\text { - Elegir a los representantes ante el Comité } \\
\text { Ejecutivo de Atención y Reparación. } \\
\text { - Elegir los representantes ante la Comisión } \\
\text { de Seguimiento y Monitoreo. } \\
\text { - Elegir a los representantes ante el Con- } \\
\text { sejo Directivo del Centro de Memoria } \\
\text { Histórica. }{ }^{29}\end{array}$ & $\begin{array}{l}\text { - Servir de escenario propicio } \\
\text { para la participación equitati- } \\
\text { va de víctimas mujeres, niñas } \\
\text { y niños, adolescentes, adul- } \\
\text { tos mayores y discapacitadas. } \\
\text { - Contar con un Plan de Trabajo } \\
\text { anual y comunicarlo a las re- } \\
\text { spectivas secretarías técnicas } \\
\text { para que estas adopten las } \\
\text { acciones correspondientes. }\end{array}$ \\
\hline
\end{tabular}

25 Decreto 4800 de 2011, art. 276.
26 Decreto 4800 de 2011 , art. 287.
27 La conformación de este Consejo Directivo no está determinada ni en la Ley 1448 de $2011 \mathrm{ni}$ en el Decreto 4800. Existe un vacío frente a cuántos miembros de la Mesa Nacional de Participación podrán intervenir en dicho escenario. 
Por último, el Decreto 4800 de 2011 dispone que las alcaldías, las gobernaciones y la Unidad Administrativa Especial de Atención y Reparación Integral a las Víctimas, coordinen el ingreso de las organizaciones de población desplazada a este nuevo esquema de mesas de participación. Las entidades gubernamentales mencionadas asumen el deber de enviar a las personerías municipales y a las defensorías regionales los listados de organizaciones que conforman las mesas municipales, departamentales y la Mesa Nacional de Fortalecimiento de Organizaciones Desplazadas para que estas queden "automáticamente inscritas". ${ }^{28}$
Por el otro lado, como segundo escenario de participación, están los Comités y Consejos Directivos de entidades gubernamentales en los que se disponen puestos para los representantes de las víctimas. Estos Comités y Consejos Directivos, coordinados por las entidades gubernamentales, son espacios en los que los representantes de las víctimas, elegidos por las mesas nacionales, departamentales y nacional interactúan con los responsables de la implementación de la Ley. La conformación de estos escenarios de participación y sus funciones específicas se exponen en el cuadro 3.

\section{Cuadro 3:}

\section{Comités y Consejos directivos: funciones y participación de las víctimas en esas instancias}

\begin{tabular}{|c|c|}
\hline $\begin{array}{l}\text { Escenario de par- } \\
\text { ticipación }\end{array}$ & Descripción del escenario \\
\hline $\begin{array}{l}\text { (i) Comité Ejecutivo } \\
\text { para la Atención y } \\
\text { Reparación de las } \\
\text { Víctimas. }\end{array}$ & $\begin{array}{l}\text { El Comité Ejecutivo para la Atención y Reparación de las Víctimas }{ }^{31} \text { es la máxima instancia de } \\
\text { decisión del Sistema Nacional de Atención y Reparación a las Víctimas. Entre sus funciones más } \\
\text { importantes están: diseñar y adoptar el conjunto de políticas, planes y estrategias para atención } \\
\text { asistencia y reparación de los beneficiarios de la Ley 1448; adoptar el Plan Nacional de Atención } \\
\text { y Reparación; apoyar y gestionar la consecución de recursos para la implementación; y hacer } \\
\text { seguimiento a la ejecución de la Ley y su normatividad relacionada. } \\
\text { El Comité está integrado por el Presidente de la República o su delegado (quien lo presidirá), el } \\
\text { Ministro del Interior o su delegado, el Ministro de Hacienda y Crédito Público o su delegado, el } \\
\text { Ministro de Agricultura o su delegado, el Director del Departamento Nacional de Planeación o su } \\
\text { delegado, el Director de la Agencia Presidencial para la Acción Social y la Cooperación Interna- } \\
\text { cional (mientras esta entidad se suprime) y el Director de la Unidad Administrativa Especial para } \\
\text { la Atención y Reparación Integral de las Víctimas. La secretaría técnica de este Comité es ejercida } \\
\text { por la Unidad administrativa que se acaba de mencionar. }\end{array}$ \\
\hline $\begin{array}{l}\text { (ii) Subcomités téc- } \\
\text { nicos }\end{array}$ & $\begin{array}{l}\text { Los subcomités técnicos son grupos de trabajo interinstitucional, encargados del diseño de la } \\
\text { política pública de prevención, asistencia, atención y reparación integral a las víctimas. Estos sub- } \\
\text { comités técnicos presentan insumos para que el Comité Ejecutivo para la Atención y Reparación } \\
\text { de las Víctimas tome decisiones sobre los planes, programas y estrategias de atención, asistencia } \\
\text { y reparación a las víctimas. } \\
\text { Sin prejuicio de que se puedan conformar más subcomités técnicos, }{ }^{32} \text { el Decreto } 4800 \text { de } 2011 \\
\text { dispone la conformación inmediata de diez (10) subcomités técnicos de trabajo entre los que } \\
\text { se destacan el de coordinación nación-territorio; el de atención y asistencia; el de prevención, } \\
\text { protección y garantías de no repetición; y el de enfoque diferencial. }\end{array}$ \\
\hline
\end{tabular}

29 Las normas relacionadas con la conformación y las funciones del Comité Ejecutivo para la Atención y Reparación de las Víctimas son: Ley 1448 de 2011, arts. 164 y 165 y Decreto 4800 de 2011, arts. 235-237 y 280

28 Decreto 4800 de 2011, art. 283.

30 Decreto 4800 de 2011, art. 238, parágrafo. 


\section{\begin{tabular}{c|c}
$\begin{array}{c}\text { Escenario de par- } \\
\text { ticipación }\end{array}$ & Descripción del escenario \\
\hline
\end{tabular}}

De acuerdo con el Decreto 4800, estos subcomités siempre deberán estar integrados por el Ministerio de Justicia y del Derecho, el Ministerio de Hacienda y Crédito Público, el Departamento Administrativo para la Prosperidad Social, el Departamento Nacional de Planeación y la Unidad (ii) Subcomités técnicos Administrativa Especial para la Atención y Reparación Integral a las Víctimas. No obstante, la conformación de estos subcomités está condicionada a las necesidades y requerimientos que defina el Comité Ejecutivo para la Atención y Reparación de las Víctimas.

De acuerdo con el art. 263 del Decreto 4800 y con el protocolo de participación (borrador, p. 159), la Mesa Nacional de Participación de Víctimas escogerá a los representantes ante los distintos subcomités entre sus miembros. Estos representantes tendrán voz pero no voto).

Los Comités Territoriales de Justicia Transicional ${ }^{33}$ tienen como objetivo principal coordinar la oferta institucional para garantizar la puesta en marcha de los planes de atención, asistencia y reparación a las víctimas que son diseñados en los escenarios nacionales de decisión (especialmente en el Comité Ejecutivo para la Atención y Reparación de las Víctimas y el Consejo Directivo de la Unidad Administrativa Especial de Gestión de Restitución de Tierras Despojadas). Estos Comités pueden conformarse tanto en el nivel municipal como en el nivel departamental y están integrados por el gobernador o el alcalde (quien lo presidirá), el secretario de Gobierno (departamental o municipal), el secretario de Planeación (departamental o municipal), el secretario de Salud (departamental o municipal), el secretario de Educación (departamental o municipal), el comandante de Brigada que tenga jurisdicción en la zona, el comandante de la Policía en la respectiva jurisdicción, el director regional del ICBF, el director regional del SENA, un representante del Ministerio Público,

(iii) Comités Territoriales de Justicia Transicional.

(iv) Consejo Directivo de la Unidad Administrativa Especial de Gestión de Restitución de Tierras Despojadas. un delegado de la Unidad Administrativa Especial de Atención y Reparación Integral y dos representantes de las víctimas del respectivo nivel departamental o municipal. En total estos comités son conformados con trece (13) miembros. La Gobernación o la Alcaldía, según el caso, ejercen la secretaría técnica con similares funciones a la secretaría ejercida por las personerías municipales y las defensorías regionales en las mesas de participación.

Por su parte, de acuerdo con el artículo 192 del Decreto 4633 de 2011 -sobre víctimas pertenecientes a pueblos indígenas - en estos se dispone un asiento para un delegado de los pueblos y comunidades indígenas del área de influencia del respectivo Comité Territorial. Este delegado es escogido por decisión de las autoridades indígenas de la zona. Igualmente ocurre con las comunidades afrodescendientes que, de acuerdo con el artículo 152 del Decreto 4635 de 2011 -sobre víctimas pertenecientes a comunidades negras, raizales, cimarrones y palenqueras - contarán con asiento para un delegado escogido por las autoridades de las comunidades de la respectiva zona en los Comités Territoriales de Justicia Transicional correspondientes.

El Consejo Directivo de la Unidad Administrativa Especial de Gestión de Restitución de Tierras Despojadas $^{34}$ es el escenario en el que se diseña, se modifica y se señalan los lineamientos para la implementación de la política de restitución. Este Consejo Directivo está integrado por el Ministro de Agricultura o su delegado (quién lo presidirá), el Ministro del Interior o su delegado, el Ministro de Hacienda o su delegado, el Ministro de Medio Ambiente o su delegado, el Ministro de Defensa o su delegado, el Director del Departamento Nacional de Planeación o su delegado, El Director General de la Unidad Administrativa Especial de Atención y Reparación Integral a las Víctimas, el Director del Incoder, el Presidente del Banco Agrario, el Presidente de Finagro, el Defensor del Pueblo, dos representantes de la Mesa Nacional de Participación de Víctimas y el Director Ejecutivo de la Unidad Administrativa Especial de Gestión de Restitución de Tierras Despojadas.

De acuerdo con el artículo 178 del Decreto 4633 de 2011 - sobre víctimas pertenecientes a pueblos indígenas - en este Consejo Directivo tendrán asiento dos representantes de los pueblos y comunidades indígenas elegidos por la Mesa Nacional de Concertación.

31 Las normas relacionadas con la conformación y las funciones de los Comités Territoriales de Justicia Transicional son: Ley 1448 de 2011, arts. 173; Decreto 4800 de 2011, arts. 252-253 y 281; Decreto 4633 de 2011, arts. 191 y 192; Decreto 4635 de 2011, arts. 151 y 152. 
De los dos escenarios de participación expuestos (las mesas, por un lado, y los comités y consejos directivos, por el otro) se entiende por "espacios claves de decisión" solo aquellos comités y consejos directivos en donde se proyectan y se toman las decisiones definitivas sobre la implementación y la ejecución de los programas de asistencia, atención y reparación a las víctimas. Concretamente, dentro del sistema de participación diseñado en la Ley 1448 y sus decretos reglamentarios, se identifican como espacios claves de decisión: (i) el Comité Ejecutivo para la Atención y Reparación de las Víctimas, (ii) los subcomités técnicos, (iii) los Comités Territoriales de Justicia Transicional y (iv) el Consejo Directivo de la Unidad Administrativa Especial de Gestión de Restitución de Tierras Despojadas.

Las mesas de participación en sus tres niveles no se consideran "espacios claves de decisión" pues estas no cuentan con autonomía para tomar decisiones frente al diseño y la implementación de la política pública de reparación. Las mesas, que son un espacio exclusivamente deliberativo entre las víctimas, solo cuentan con autonomía para tomar decisiones respecto a su funcionamiento y organización interna. Salvo por la elección que hacen estas mesas de los voceros y representantes de las víctimas ante los comités y los consejos directivos, su capacidad decisoria frente al diseño e implementación de la política pública es prácticamente nula.

Ahora bien, además de lo anterior, puede decirse que la participación de las víctimas en los espacios que denomino claves, se reduce a una participación formal por dos razones principa- les. ${ }^{33}$ Primera, porque no se fijan mecanismos precisos para evaluar el peso específico de las propuestas de las víctimas en el diseño y la implementación de la política pública; y, segundo, porque en la conformación de algunos de los comités y consejos directivos en los que se definen los planes y las estrategias de implementación, el gobierno ni siquiera está obligado a convocar a los representantes de las víctimas. Esto supone que la participación efectiva de las víctimas depende de la buena voluntad del gobierno de turno. Incluso, en algunos de estos espacios claves de decisión (por ejemplo, en el Comité Ejecutivo para la Atención y Reparación) aun invitando a los representantes de las víctimas, en la reglamentación se señala que estos tendrán voz pero no voto para intervenir en la toma de decisiones.

Ante la ausencia de mecanismos que permitan evaluar el impacto real de las propuestas de las víctimas en el diseño de las políticas, puede decirse que la participación es concebida por la misma norma como un mecanismo para que los beneficiarios de las políticas a implementar conozcan y opinen sobre estas, pero no para que sean actores activos en su construcción y evaluación (Chiarrello, 2011, p. 404). La ausencia de mecanismos que garanticen que determinadas propuestas deban ser estudiadas y sometidas a consideración de los comités y consejos directivos de la misma forma en que son estudiadas las propuestas del gobierno, se

33 Entiendo por participación formal la ausencia de mecanismos (como el poder de veto, por ejemplo) que les garanticen a los representantes de las víctimas que sus opiniones respecto del diseño y la implementación de los planes de atención, asistencia y reparación tengan efecto vinculante. 
presta para que en la práctica las sugerencias y comentarios de los representantes no siempre sean tenidos en cuenta. ${ }^{34}$ Aunque las normas sobre participación exigen que las entidades gubernamentales respondan a cada una de las sugerencias o comentarios de las víctimas y sus representantes, el mecanismo de participación en conjunto está orientado principalmente a la recolección de propuestas que, independientemente de su pertinencia y valor, generalmente son archivadas o incluidas ocasionalmente en los reportes oficiales sobre el funcionamiento del sistema de participación. ${ }^{35}$

Si bien se puede cuestionar el nivel de representatividad de los voceros de las víctimas que participan en los espacios claves de decisión (pues la cooptación es un riesgo latente), lo cierto es que la capacidad de proponer reformas a la política pública no puede depender de la legitimidad de los representantes. Como es natural en cualquier proceso democrático, puede presentarse el caso de que los representantes hagan propuestas de política que no sean compartidas por todas las víctimas a las que representan. No obstante, esta ausencia de legitimidad de las propuestas no debe soslayar el deber que tienen los comités y consejos directivos de estudiar a profundidad las recomendaciones y sugerencias presentadas por los representantes de las víctimas.

34 Entrevista a Ángel María, ibíd., nota 6 y a Tania Bohórquez, líder de víctimas del departamento de Sucre, Bogotá, octubre 24 de 2012.

35 Un problema similar es explicado por Chiarrello (2011, p. 404) al describir el funcionamiento del sistema de participación de población desplazada.
Además, puede decirse que la participación también es formal en la medida en que, de acuerdo con las mismas normas, las secretarías técnicas de algunos de los comités y consejos directivos ni siquiera están obligadas a convocar a los representantes de las víctimas para conocer sus opiniones o propuestas. Este problema es particularmente visible respecto de la conformación del Comité Ejecutivo del Sistema y sus respectivos subcomités técnicos de apoyo. Aun cuando los representantes de las víctimas tienen garantizados asientos en los Comités Territoriales de Justicia Transicional y el Consejo Directivo de la Unidad Administrativa Especial de Gestión de Restitución de Tierras Despojadas, no pasa lo mismo con el Comité Ejecutivo para la Atención y Reparación de las Víctimas y sus respectivos subcomités técnicos.

Por ejemplo, aunque el Decreto 4800 de 2011 (art. 280) señala que una de las funciones específicas de la Mesa Nacional de Participación es escoger a los representantes ante el Comité Ejecutivo como si estos tuvieran intervención permanente en ese escenario de decisión, lo cierto es que en la conformación de ese Comité (de acuerdo con lo dispuesto en el artículo 164 de la Ley 1448 de 2011) no están contemplados asientos fijos para los representantes de las víctimas. De acuerdo con el artículo 165 párr. 2 de la Ley 1448, la secretaría técnica del Comité solo asume la facultad de invitar a los representantes cuando lo juzgue conveniente.

Sin embargo, la "facultad" de invitar a los representantes se transforma, en la práctica, en una manera de no tenerlas en cuenta, al menos, por 
dos razones. Primera, porque al no estar obligadas a invitarlos, las entidades gubernamentales prefieren contar con la intervención de las víctimas solo cuando los planes y las estrategias ya están diseñados y lo que se busca es que sus representantes conozcan y aprueben lo que ya han decidido con anterioridad. Segunda, porque las entidades pueden decidir invitar a los representantes solo en determinadas situaciones y esto les impide a las víctimas tener un conocimiento integral de los procesos de toma de decisiones. Al no poder asistir a todas las reuniones los representantes están condenados a conocer solo parcialmente el proceso de diseño e implementación de los planes y estrategias de atención, y esto les impide, por ejemplo, preparar propuestas oportunas que puedan ser tenidas en cuenta por los hacedores de políticas públicas.

Por su parte, a pesar de la importancia de los subcomités técnicos para la definición de las políticas de asistencia, atención y reparación, ni en la Ley 1448 de 2011 ni en el Decreto 4800 se precisa con claridad la forma en la que las víctimas, a través de sus representantes, podrán intervenir ante estos subcomités. No se dice nada sobre el mecanismo de elección de los representantes ante estas instancias y tampoco sobre el alcance de su participación. Si bien algunos de estos aspectos se aclaran en el protocolo de participación (Resolución del 8 de mayo de 2013, Congreso de la República), este se limita (párr. 1 art. 38) a señalar que los representantes deben ser convocados con tres días de anterioridad y a libre consideración de los miembros del subcomité específico. Admite que los representantes tengan voz en las sesiones de los subcomités a las que sean invitados y obliga a los miembros del subcomité a ofrecer respuestas motivadas a los representantes sobre sus propuestas. Sin embargo, la "vaguedad" con la que está prevista la posibilidad de que los representantes participen en estos espacios es entendida por algunos líderes como una exclusión directa de los escenarios claves de decisión. ${ }^{36}$

Estas dificultades del sistema de participación diseñado en la Ley 1448 de 2011 se hicieron evidentes en el funcionamiento de un sistema de participación similar: las mesas de participación de población desplazada. Como lo mencionó la Corte Constitucional en varios autos de seguimiento a la sentencia T-025 de $2004^{37}$ y como lo estudió la Comisión de Seguimiento a la Política Pública de Atención a Población Desplazada, ${ }^{38}$ las mesas de participación de desplazados fueron un ejemplo de lo poco eficiente que son las mesas para garantizar que las víctimas puedan hacer parte de los "espacio claves de decisión".

Por ejemplo, en los últimos informes de la Comisión de Seguimiento sobre el funcionamiento y la utilidad del sistema de mesas de participación de población desplazada se concluyó que,

36 Entrevista a Tania Bohórquez, Ibíd., nota 35; a Leonel Uribe Hernández, Ibíd., nota 5 y a Edwin Mendoza, Ibíd., nota 5.

37 Corte Constitucional, Auto 008 de 2009, M. P.: Manuel José Cepeda; Auto 219 de 2011, M. P.: Luis Ernesto Vargas.

38

Entre los informes de la Comisión de Seguimiento a la Política Pública sobre Desplazamiento Forzado se puede mencionar el Estado de avance de la realización del derecho a la participación efectiva de la población desplazada, de junio de 2001. 
entre otros, uno de los problemas estructurales de la participación es que ni las instituciones del Estado ni las víctimas contaban con mecanismos que les permitieran evaluar el impacto de las propuestas que surgían de las mesas, sobre el diseño y la implementación de la política de atención y reparación. Igualmente, estos informes de la Comisión y los autos de la Corte Constitucional daban cuenta de una "participación" exclusivamente formal, en la medida en que los representantes de las mesas no tenían incidencia en el diseño del PIU -Plan Integrado Único- que era considerado la herramienta de planeación estratégica dentro de la cual las autoridades locales organizaban los programas de atención a víctimas del desplazamiento. ${ }^{39}$

En su momento, la Comisión de Seguimiento criticó que los representantes de las mesas no contaran con voz y voto en algunos de los espacios en donde se tomaban las decisiones de política y que no fueran convocados de forma ordenada a las reuniones en las que las autoridades locales, departamentales y nacionales tomaban decisiones sobre el funcionamiento de los programas de atención a población desplazada. La Comisión cuestionó, igualmente, la interlocución entre esas mesas, las instituciones del Estado y las comunidades de base. Sobre esto, se dijo que las mesas no solo no garantizaban la participación efectiva de las víctimas en el diseño y la implementación de la política pública de atención y reparación, sino que, además, estas no habían cumplido su rol de filtrar y solidificar

Corte Constitucional, Auto 219 de 2011, M. P.: Luis Ernesto Vargas. las propuestas de las comunidades con miras a que pudieran ser tomadas en cuenta por parte de los hacedores de políticas públicas.

\section{El problema de la debilidad de las instituciones para la participación en lo local}

La Ley 1448 , el Decreto 4800 y el protocolo de participación contemplan distintos escenarios de participación de orden nacional y local que deberán actuar simultáneamente. Si bien el Decreto 4800 contiene algunas normas que pretenden garantizar la coordinación entre las distintas instancias que intervienen en la implementación de los programas de asistencia, atención y reparación, lo cierto es que la proliferación de instancias de participación, como fue posible constatarlo en el sistema de participación para población desplazada, ${ }^{40}$ no garantiza la participación efectiva de las víctimas ni en la formulación de las políticas (en el orden nacional) ni en la implementación de los programas (en el orden local). En la presente sección se señalan las razones por las que el sistema de mesas de participación se ve directamente afectado por los problemas de coordinación nación-territorio y por la ausencia de instituciones estatales sólidas en algunos municipios y departamentos del país.

El sistema de participación para población desplazada, que fue implementado por el Gobierno

40 Los problemas de coordinación nación-territorio en la implementación de las políticas de atención a población desplazada son descritos y desarrollados por la Corte Constitucional en dos decisiones centrales: el Auto 008 de 2009, M. P.: Manuel José Cepeda y el Auto 383 de 2012, M. P.: Luis Ernesto Vargas. 
Nacional y Acción Social como una respuesta a las órdenes de la Corte Constitucional en los autos 116 de 2008, 008 de 2009 y 383 de 2010, contaba con mesas en el orden territorial (municipales y departamentales) que debían escoger a los representantes ante un comité interinstitucional conformado por las entidades locales responsables de la implementación de las medidas de atención a población desplazada. El esquema era bastante similar al que se adoptó en la Ley 1448 de 2011: las víctimas, organizadas en mesas, escogen a sus representantes ante un comité municipal o departamental (Comités Territoriales de Justicia Transicional), con el objetivo de que sean sus interlocutores directos de las entidades públicas responsables de implementar los programas diseñados por el orden nacional (Comité Ejecutivo para la Atención y Reparación Integral de las Víctimas).

La Corte Constitucional, en distintas oportunidades, identificó los problemas de coordinación nación-territorio derivados de la proliferación de instancias de participación y decisión sobre el tipo de políticas de atención que se debían implementar para la población desplazada. El esquema de la Ley 1448, si bien avanza en diseñar algunos mecanismos de rendición de cuentas de las entidades territoriales con miras a corregir los problemas identificados por la Corte en el sistema de atención a población desplazada, no garantiza que se resuelvan los problemas de coordinación que impiden que las víctimas sean actores activos en el diseño y la implementación de las políticas con las que el Estado piensa atenderlas, al menos, por dos razones:
Primera, el sistema de participación por mesas, si bien asegura que las víctimas podrán tener acceso a información que las entidades locales y nacionales produzcan sobre el tipo de medidas que se deberán implementar, no garantiza que el acceso a esa información sea completo y uniforme, entre otras, porque la eficiencia en la construcción y el funcionamiento de las mesas y en la interlocución de estas con las entidades territoriales depende de entidades públicas que son particularmente débiles en algunas regiones. ${ }^{41}$

Solo por mencionar algunos ejemplos, en el Auto 219 de 2011, la Corte Constitucional recoge observaciones de distintas mesas departamentales de participación de población desplazada ${ }^{42}$ y concluye que: (i) frente a los requerimientos de las víctimas desplazadas no siempre está garantizado el acceso a la información o simplemente las respuestas institucionales son inoportunas; (ii) las administraciones locales no entregan la información solicitada; (iii) no hay suficiente acompañamiento por parte de las

41 Entrevista a Juliana Vargas, investigadora del cıJus, experta en la participación de mujeres desplazadas. Bogotá, febrero 20 de 2012.

42 Concretamente de: la Mesa Departamental de Fortalecimiento a Organizaciones de Población en situación de Desplazamiento de Putumayo; Mesa de Fortalecimiento de Organizaciones de Población Desplazada, Barrancabermeja; Mesa Municipal de FortalecimientoOrganizaciones de Población Desplazada, Santiago de Cali; Organización de Población Desplazada del Departamento del Caquetá; Mesa de Fortalecimiento a OPD Floridablanca; Mesa Departamental de Fortalecimiento a Organizaciones de Población Desplazada del Cesar; Representantes de la Población Desplazada de Tuluá; Mesa Departamental de Población Desplazada de Nariño; Asociación de Juntas de Desplazados de La Guajira; Mesa Departamental de Fortalecimiento a OPD del Cauca; Asociación de Desplazados ASODESC; Consejo Comunitario Mayor de la Asociación Campesina Integral del AtratoCocomacia; Mesa de Fortalecimiento a Organizaciones de Población Desplazada de Norte de Santander; Organizaciones de Población Desplazada del Departamento del Cauca. 
entidades territoriales y del SNAIPD ${ }^{43}$ para la convocatoria de las mesas de participación; (iv) los comités de atención a la población desplazada no funcionan coordinadamente de acuerdo con procedimientos preestablecidos; (v) se utiliza la participación para cumplir con los requisitos de socialización de los proyectos, a pesar de que se trata de mera asistencia a reuniones; (vi) ciertas organizaciones de población desplazada hacen el papel de legalizar gastos de las administraciones municipales (sin que esto deba ser parte de sus funciones) y (vii) para diferentes encuentros las administraciones escogen a ciertos líderes para representar a la población desplazada sin consultar a todas las organizaciones intervinientes.

Estos problemas, que fueron identificados por la Corte en 2011, se profundizan en la medida en que la Ley 1448 de 2011 no previó ningún mecanismo de transición entre las mesas de participación de población desplazada y las mesas de participación de víctimas del conflicto armado. La debilidad de algunas instituciones estatales en el ámbito local redunda en ausencia de coordinación y organización de las nuevas mesas de participación diseñadas en la Ley 1448 de 2011. La debilidad de las instituciones estatales locales se manifiesta en la ausencia de políticas y programas que permitan articular el trabajo adelantado por las mesas de participación de desplazados con el nuevo trabajo encomendado a las mesas de participación para las víctimas del conflicto armado. La ausencia de mecanismos de transición entre un sistema

43 Sistema Nacional de Atención Integral a la Población Desplazada. de participación y otro ha generado, además, disputas y fisuras entre las organizaciones de víctimas, los representantes y los voceros. Solo un ejemplo del tipo de problemas que se presentan: algunos voceros de las mesas de población desplazada sostienen que ese sistema de participación debe seguir operando paralelamente al nuevo esquema diseñado en la Ley de Víctimas. En la actualidad, algunas organizaciones se han divido como consecuencia de que unas apuestan por la integración entre mesas de desplazados y mesas de víctimas y otras por la independencia entre un sistema de participación y el otro.

Por su parte, el nuevo diseño de las mesas de víctimas, además de replicar un sistema que ha fallado mucho en lo local, agregó una nueva dependencia de participación en el municipio al darle al personero municipal la función de hacer de secretaría técnica de las mesas municipales de víctimas. Ello crea problemas de abundancia de funciones y escasez de recursos para las personerías de muchos municipios, amén de extender la posible cooptación de la Alcaldía por Grupos Armados al Margen de la Ley a las mismas mesas. En el caso de la conformación de las mesas del orden municipal, vale la pena resaltar que algunos personeros municipales se han quejado de la cantidad de funciones que deben desempeñar. ${ }^{44}$ Las personerías, que cumplirán el papel de secretarías técnicas de las mesas municipales, son entidades públicas

44 Sobre el particular, se puede referir la intervención del personero de Leticia (Amazonas) en el proceso de consulta del Decreto 4633 de 2011 correspondiente a víctimas pertenecientes a pueblos y comunidades indígenas. Leticia, Amazonas, octubre 24 de 2011. 
que por lo general no cuentan con los recursos económicos y humanos suficientes para convocar regularmente y poner en funcionamiento las mesas municipales. Esto crea desequilibrios en la forma en que las organizaciones de víctimas y las ODDV acceden a la información en distintos lugares del territorio, generando desorganización y algunas veces motivando que se implementen procedimientos contrarios a los dispuestos en las leyes y los protocolos de orden nacional.

Segundo, las gobernaciones y alcaldías no siempre actúan de manera coordinada por más que esa sea una de sus responsabilidades. Si bien el Decreto 4800 ordena a estas dos entidades territoriales diseñar y ejecutar planes de acción territorial (que son la hoja de ruta de la acción local de atención, asistencia y reparación a las víctimas), no fija un término específico para su formulación, no señala la forma en que los planes diseñados por las alcaldías deben estar articulados con los planes diseñados por las respectivas gobernaciones y no garantiza que los planes sean concertados con las víctimas.

En este caso, vuelve a presentarse un problema de tiempos para la implementación y la coordinación entre los distintos planes, y de participación efectiva de las víctimas en el diseño de estos. El problema de tiempos radica en que no se señala con precisión cuándo deben estar listos los Planes de Acción Territorial. Al no fijar un plazo concreto, las gobernaciones y las alcaldías actúan de manera autónoma frente al diseño de sus propios proyectos y cada cual lo tendrá listo en tiempos diferentes, lo que hace muy difícil que la Unidad Administrativa Especial de Atención y Reparación Integral pueda tener un control efectivo en cuanto a que todos estén articulados con el Plan Nacional de Atención y Reparación Integral.

El problema de coordinación radica en que las gobernaciones y las alcaldías, al ser autónomas frente al diseño de sus propios planes de acción, tienen en cuenta distintas variables de análisis sobre las necesidades de las víctimas en el territorio. Aunque el Decreto 4800 obliga a que los planes de las gobernaciones se ajusten con los de las alcaldías, la experiencia del sistema de participación de población desplazada muestra que, en la práctica, esa autonomía tiene como consecuencia que las gobernaciones y las alcaldías no articulan sus planes de acción y en ocasiones actúan de manera dispersa o contradictoria, haciendo que las víctimas sientan confusión sobre con qué tipo de programas cuentan como parte de la política de asistencia, atención y reparación.

El problema de participación de las víctimas está asociado a los dos problemas señalados anteriormente. Al no existir un plazo concreto para el diseño del Plan de Acción Territorial, no es claro si para su conformación las entidades territoriales deben contar con las observaciones hechas por las mesas de participación de víctimas o por las de los representantes de las víctimas en los Comités Territoriales de Justicia Transicional. La ausencia de un plazo concreto contribuye a que la participación de las víctimas se convierta en la aprobación de propuestas estatales prefijadas, en la medida en que los planes pueden ser sometidos a consideración de las mesas y de 
los representantes en los respectivos comités cuando ya estén construidos. Adicionalmente, como los planes de acción territorial tendrán una vigencia de cuatro años, en concordancia con los tiempos de las administraciones locales (art. 255 Decreto 4800 de 2011), en la práctica estos pueden cambiar bruscamente de dirección dependiendo del gobernador o el alcalde de turno.

Igualmente, la falta de plazos concretos y la proliferación de instancias de participación se traduce, en la práctica, en que algunos planes sí son sometidos a consideración de las víctimas y otros no. Aquí la participación de las víctimas depende más de la eficiencia y la voluntad política de las entidades territoriales, de ahí que algunas diseñan sus respectivos planes teniendo en cuenta algunas observaciones de las mesas y los representantes, mientras otras lo hacen al margen de las sugerencias de las víctimas que, como se sabe, no son vinculantes en ningún caso y respecto de ningún tema.

\section{EL POTENCIAL TRANSFORMADOR DE LA PARTICIPACIÓN POR MESAS}

Como se aprecia en la sección anterior, el sistema de participación adoptado en la Ley 1448 de 2011 no fue usado para la construcción del Decreto 4800, el Plan Nacional de Atención y Reparación Integral y el Conpes 3726 de 2012 (que son tres de los instrumentos jurídicos más importantes de la reglamentación de los planes y programas de atención, asistencia y reparación). Este esquema tiene problemas estructu- rales y específicos que reducen la participación de las víctimas a la simple aprobación de políticas prefijadas por el Estado. No obstante, en la presente sección señalo tres potencialidades concretas que tiene la implementación de este esquema de participación para el fortalecimiento de las organizaciones que, eventualmente, podrán realizar algún tipo de sugerencia frente al diseño e implementación de los planes de asistencia, atención y reparación a través de las mesas de participación. El desarrollo de estas potencialidades apunta a consolidar a las mesas de participación como espacios autónomos de decisión de las víctimas, en los que estas toman decisiones de presupuesto y cuentan con mecanismos de control y veeduría sobre la implementación de programas adelantados en el marco de la atención y reparación.

Si bien el sistema de participación de la Ley 1448 se encuentra divido en dos escenarios principales (las mesas y los comités y consejos directivos en los que participan los representantes de las víctimas), aquí me concentro en resaltar algunas potencialidades que pueden convertir al escenario de las mesas de participación en un espacio de empoderamiento de las víctimas. Las fortalezas que se señalan surgen de conversaciones con distintos actores (investigadores en el tema ${ }^{45}$ y víctimas ${ }^{46}$ ) que destacan aspectos positivos de la implementación de modelos de participación ciudadana por mesas.

45 Entrevista a Angeliza Zamora, Ibíd., nota 2; a Alejandra Saffon, ibíd., nota 2 y a Juliana Vargas, Ibíd., nota 42. 
Las mesas de participación están concebidas como escenarios que son orientados por las mismas víctimas y que se prestan para que estas interactúen a través de sus organizaciones. Aun cuando el funcionamiento y la coordinación de las mesas es responsabilidad de la entidad pública que ejerza la respectiva secretaría técnica, lo cierto es que este escenario se puede convertir en un verdadero espacio de participación igualitaria en la medida en que se permita a las propias organizaciones planear la agenda de la sesiones, decidir cuándo y en qué tiempo se convocan las reuniones, contar con la participación de funcionarios públicos del orden territorial cuando así lo consideren conveniente y permitir que de estas mesas salgan propuestas de política vinculantes en algunos temas específicos que deberán implementarse en el respectivo Plan de Acción Territorial. Si bien a lo largo del capítulo se han evidenciado los cuestionamientos a la representatividad de las personas que participan en las mesas, en la medida en que los representantes deban asumir funciones respecto de las cuales sea posible medir su desempeño, las comunidades de base pueden hacerles un control juicioso del tipo de labor que estos cumplen. Si las mesas de participación carecen de todo poder propositivo y su funcionamiento es responsabilidad exclusiva de las secretarías técnicas (que pueden ser débiles en algunos municipios), la cooptación de líderes y la ausencia de incentivos reales para participar seguirán caracterizando la relación entre la sociedad civil y el Estado, al menos en lo que a representantes de víctimas se refiere.
Varios actores destacan que el sistema de participación por mesas tiene una potencialidad transformativa, en la medida en que permite que algunas organizaciones (tanto de víctimas como de defensoras de los derechos de las víctimas) se reconozcan mutuamente e identifiquen puntos de trabajo que son comunes en sus respectivas agendas. Esto contribuye a fortalecer y organizar el trabajo de los grupos de víctimas como redes sociales que pueden tramitar con mayor eficiencia algunas solicitudes, y promover con mayor fuerza cambios concretos en las políticas de asistencia, atención y reparación. Igualmente, el hecho de que las mesas operen como escenarios de reconocimiento entre las organizaciones puede contribuir a un intercambio de información y experiencias entre las que más conocimiento tienen de algunos temas y aquellas que acaban de nacer, lo cual es a la vez una transformación en términos educativos y de sensibilización de las mismas víctimas frente a aspectos que desconocían o de los funcionarios públicos frente al fenómeno de violación de derechos humanos. Sobre este punto se puede decir algo adicional: ser escogido como vocero o representante no es sinónimo de dominio de los textos legales pertinentes (Ley 1448 y demás normas reglamentarias) ni de conocer los desafíos administrativos y logísticos propios de una función social de relevancia como la que se va a desempeñar. El protocolo de participación debe garantizar una capacitación continua y sistemática de los líderes de las víctimas, para que estos conozcan a profundidad y en detalle los matices jurídicos que caracterizan la reglamentación del sistema de participación, por un lado, y las me- 
didas de asistencia, atención y reparación, por el otro. Solo sobre la base de un conocimiento sólido y común (del que sean propietarios tanto las víctimas como las instituciones del Estado) se puede garantizar una participación en "igualdad de condiciones" o, por lo menos, un diálogo entre pares que dominan un tema específico. Esta capacitación, además, debe versar sobre los deberes que se desprenden de la coadministración de recursos públicos (en caso que se les permita a las víctimas disponer de algunos fondos para libre destinación de acuerdo con lo que se concierte en las respectivas mesas de participación).

Varios actores destacan la debilidad de las mesas como un escenario de participación, basados en que su administración y coordinación es responsabilidad de entidades públicas que son particularmente débiles en ciertas regiones del territorio nacional. Una propuesta concreta que contribuiría a avanzar hacia un modelo de participación por mesas como factor de "empoderamiento" es que la administración de los recursos para el funcionamiento de estas sea concedida a una junta de voceros que, además de rendir cuentas periódicas pueda tener autonomía para el manejo, de acuerdo con las prioridades y necesidades planteadas por las víctimas, por ejemplo, para convocar movilizaciones y encuentros de las organizaciones no solo en el nivel local, y para promover campañas de visibilización frente a algunos temas concretos. Como es obvio, la coadministración de recursos supone también la corresponsabilidad que se deriva de la administración de dineros públicos. Las víctimas "empoderadas" responderían, na- turalmente, por la debida administración de los recursos que se les permita y para la destinación que consideren pertinente.

El sistema de participación por mesas es un escenario propicio para el fortalecimiento político de las organizaciones sociales de base. Este sistema (y sus mecanismos de vocería y representatividad) obliga a las víctimas a organizarse (al menos seminalmente) alrededor de soluciones a problemas comunes. No obstante, si el sistema no garantiza recursos (logísticos y económicos) para que los líderes puedan mantener una relación constante y fluida con las "bases" sociales que los han elegido, se corre el riesgo de burocratizar la participación. Por esta razón, el Estado debe promover (asumiendo compromisos concretos en el protocolo de participación) que los representantes y voceros se mantengan en contacto constante con las víctimas en el territorio, comprometiéndose, por ejemplo, a proveer acompañamiento a los voceros y representantes de las víctimas en las distintas fases de implementación de las rutas de asistencia, atención y reparación.

Dado que es una realidad que las distintas instituciones a lo largo y ancho de la geografía nacional trabajan a ritmos diferentes (de acuerdo con su capacidad administrativa y presupuestal), el protocolo de participación puede promover mecanismos sólidos de veeduría por parte de las víctimas a la implementación de las obligaciones de las alcaldías y gobernaciones. Por ejemplo, se pueden garantizar espacios de participación de las víctimas en los concejos municipales y las asambleas departamentales, de 
manera que puedan realizar el control político pertinente a los alcaldes y gobernadores que no cumplan con los compromisos asumidos en el Plan de Acción Territorial.

La falta de claridad sobre el alcance de la participación de las organizaciones defensoras de derechos de las víctimas puede generar divisiones políticas entre las víctimas y quienes tradicionalmente han fungido como sus defensores. Es prioritario que el protocolo de participación defina taxativamente el nivel de representatividad de esas organizaciones, dándoles, principalmente, el rol de acompañantes y garantes. Por lo general, las organizaciones defensoras de derechos de las victimas tienen mayor experiencia en procesos organizativos y de intervención política y jurídica, y el protocolo podría asignarles funciones precisas en la capacitación a los líderes de víctimas que tienen vocería ante los que han sido denominados en este capítulo "escenarios claves de participación”. Igualmente, estas organizaciones pueden explotar su experiencia específica interviniendo y haciéndose responsables de la ejecución de programas puntuales de rehabilitación, reparación o satisfacción.

\section{CONCLUSIONES}

Entre los problemas del sistema referidos a lo largo del presente documento, se señaló que está construido para la participación de personas que no confían en el Estado, y que la desconfianza de las víctimas hacia las instituciones se profundiza como consecuencia de que el Estado incumple algunos de los compromisos asu- midos y crea expectativas en las víctimas que, al no ser satisfechas, generan frustración.

También se mostró que el sistema de participación por mesas tiene tres debilidades principales: (i) falta de coherencia en los tiempos para el diseño de todo lo planeado en la Ley 1448 de 2011, falla estructural que tuvo como consecuencia que no estuviera conformado y en funcionamiento para el momento en que el Gobierno debía tomar las decisiones más trascendentales en relación con la política pública de atención y reparación; (ii) falta de participación real de los representantes de las víctimas en los aquí denominados "espacios claves de participación", al punto de afirmar que esta quedó reducida a una formalidad puesto que no cuentan con voz y voto en donde se toman las decisiones definitivas sobre las políticas de atención y reparación; (iii), un problema de funcionamiento y eficiencia que es consecuencia de las debilidades de las instituciones en el ámbito local (municipios y gobernaciones), particularmente en lo relacionado con la coordinación naciónterritorio y en la articulación en la construcción de los planes de acción territorial.

Adicionalmente, se mencionaron las tensiones que surgen como consecuencia de que la Ley 1448 de 2011 no previó ningún mecanismo de transición entre las mesas de participación de población desplazada y las mesas de participación de víctimas del conflicto armado, circunstancia que incide principalmente en la ausencia de políticas y programas que permitan articular el trabajo adelantado por estos dos mecanismos en el nivel local, y en la generación de disputas y 
fisuras entre las organizaciones de víctimas, los representantes y los voceros.

Por otro lado, el diseño de las mesas de víctimas, además de replicar un sistema que ha fallado mucho en lo local (pues se considera que tiene bastantes similitudes con el sistema de participación a población desplazada), agregó una nueva dependencia al darle a la personería municipal la función de secretaría técnica de las mesas municipales de víctimas. Ello crea problemas de abundancia de funciones y escasez de recursos para la Personería de muchos municipios, amén de extender la posible cooptación que ya se da en la Alcaldía por grupos armados al margen de la ley, también a las mesas. En cuanto a la función de la Personería municipal respecto a las mesas, vale la pena recordar que algunos personeros se han quejado de la cantidad de funciones que deben desempeñar, y han recordado que son entidades públicas que por lo general no cuentan con los recursos económicos y humanos suficientes para convocar regularmente y poner en funcionamiento las mesas municipales. Esto genera desequilibrios en la forma en que las organizaciones de víctimas y las oDDV acceden a la información en los distintos lugares del territorio, generando desorganización y algunas veces la implementación de procedimientos contrarios a los dispuestos en las leyes y los protocolos de orden nacional.

No obstante lo anterior, considero que el sistema de participación diseñado en la Ley 1448 de 2011 tiene algunas potencialidades que, de ser explotadas, contribuirían a aumentar el "empoderamiento" de las víctimas frente a la definición de políticas públicas que las afectan directamente. Para empezar, debe convertirse en un escenario propicio para el fortalecimiento político de las organizaciones sociales de base (y sus mecanismos de vocería y representatividad), toda vez que permite a las víctimas encontrarse y buscar soluciones a problemas comunes. Sin embargo, si el sistema no garantiza recursos (logísticos y económicos) para que los líderes puedan mantener una relación constante y fluida con las "bases" sociales que los han elegido, se corre el riesgo de burocratizar la participación. Por esta razón, el Estado debe promover (asumiendo compromisos concretos en el protocolo de participación) que los representantes y voceros se mantengan en contacto constante con las víctimas en el territorio, y proveer acompañamiento a los voceros y representantes de las víctimas en las distintas fases de implementación de las rutas de asistencia, atención y reparación.

En la misma vía, se señaló que si bien el funcionamiento y la coordinación de las mesas es responsabilidad de la entidad pública que ejerce la respectiva secretaría técnica, lo cierto es que este escenario se puede convertir en un verdadero espacio de participación igualitaria, en la medida en que se permita a las propias organizaciones planear la agenda de las sesiones, decidir cuándo y en qué tiempo se convocan las reuniones, contar con la presencia de funcionarios públicos del orden territorial cuando así lo consideren conveniente y permitir que sus propuestas de política sean vinculantes en algunos temas específicos y deban implementarse en el respectivo Plan de Acción Territorial. 
En cuanto a los representantes, aunque se haya cuestionado su representatividad en las mesas, considero que en la medida en que estos deban asumir funciones respecto de las cuales sea posible medir su desempeño, las comunidades de base pueden hacerles un control juicioso, que debe contemplar el aspecto jurídico, político y rendición de cuentas.

En conclusión, el sistema de participación adoptado en la Ley 1448 de 2011 es ambicioso y complejo. Supone la creación de múltiples instancias de interlocución de las víctimas en los niveles local y nacional, y la interacción de actores con distintos intereses, en espacios en los que se les pide alcanzar un consenso. Este sistema, como se ha demostrado a lo largo de este texto, tiene algunos problemas estructurales y no ha podido ser implementado de forma eficiente (aun cuando ya han pasado más de dos años desde la promulgación de la Ley 1448 de 2011). Sin embargo, no se puede desconocer la posibilidad de hacer de él una herramienta útil, siempre y cuando se ajusten algunas de las reglas de funcionamiento que impiden a las víctimas tener autonomía en el manejo de algunos recursos o intervenir directamente en su implementación (asumiendo la responsabilidad de desarrollar programas específicos de reparación, rehabilitación o satisfacción).

\section{Bibliografía}

Acción Social. (2010). Protocolo de participación de organizaciones de población desplazada. Bogotá: oPD.
Cámara de Representantes. (2012). Proyecto de Ley Estatutaria de Participación Ciudadana. Gaceta del Congreso de la República, nº 346 de 2012.

Centro Internacional para la Justicia Transicional. (12 de octubre de 2010). A propósito del proyecto de ley de víctimas. Apuntes elementales para el debate. Recuperado de http:// es.ictj.org/images/content/2/2/2222.pdf

Comisión de Seguimiento a la Política Pública de Desplazamiento Forzado. (11 de septiembre de 2011). Reglamentación y desarrollo de la Ley 1448. Bogotá.

Comisión de Seguimiento a la Política Pública de Desplazamiento Forzado. (Junio, 2010). Estado de avance y realización del derecho a la participación efectiva de la población desplazada.

Corte Constitucional. Sentencia T-025 de 2004. M. P.: Manuel José Cepeda.

Corte Constitucional. Auto 383 de 2010. M. P.: Luis Ernesto Vargas.

Corte Constitucional. Auto 008 de 2009. M. P.: Manuel José Cepeda.

Corte Constitucional. Auto 116 de 2008. M. P.: Manuel José Cepeda.

Corte Constitucional. Sentencia T-397 de 2004. M. P.: Manuel José Cepeda. 
Corte Constitucional. Sentencia T-719 de 2003. M. P.: Manuel José Cepeda.

Fundación Social. (2011a). Informe de sesión de debate del Proyecto de Ley de Víctimas. 24 de mayo de 2011. Bogotá.

Fundación Social. (2011b). Informe de sesión de debate del Proyecto de Ley de Víctimas. 12 de abril de 2011. Bogotá.

Fundación Social. (2011c). Informe de sesión de debate del Proyecto de Ley de Víctimas. 11 de abril de 2011. Bogotá.

Fundación Social. (2011d). Informe de sesión de debate del Proyecto de Ley de Víctimas. 06 de abril de 2011. Bogotá.

Fundación Social. (2011e). Informe de sesión de debate del Proyecto de Ley de Víctimas. 05 de abril de 2011. Bogotá.

Fundación Social. (2011f). Informe de sesión de debate del Proyecto de Ley de Víctimas. 30 de marzo de 2011. Bogotá.

Fundación Social. (2011g). Informe de sesión de debate del Proyecto de Ley de Víctimas. 23 de marzo de 2011. Bogotá.

Fundación Social. (2011h). Informe de sesión de debate del Proyecto de Ley de Víctimas. 22 de marzo de 2011. Bogotá.

Fundación Social. (2011i). Informe de sesión de debate del Proyecto de Ley de Víctimas. 16 de marzo de 2011. Bogotá.
Fundación Social. (2011j). Informe de sesión de debate del Proyecto de Ley de Víctimas. 15 de marzo de 2011. Bogotá.

Fundación Social. (2011k). Informe de sesión de debate del Proyecto de Ley de Víctimas. 08 de marzo de 2011. Bogotá.

Fundación Social, Organización Internacional para la Migraciones y usAID. (Septiembre, 2011). Participación de las víctimas en el marco de la Ley 1448 de 2011 o Ley de Víctimas. Septiembre de 2011. Bogotá.

Subcomité de Participación. (2011). Acta No. 1 del 6 de septiembre de 2011. Ministerio de Justicia y del Derecho (Dirección de Justicia Transicional). Bogotá.

Subcomité de Participación. (2011). Acta No. 2 del 13 de septiembre de 2011. Ministerio de Justicia y del Derecho (Dirección de Justicia Transicional). Bogotá.

Subcomité de Participación. (2011). Acta No. 3 del 15 de noviembre de 2011. Ministerio de Justicia y del Derecho (Dirección de Justicia Transicional). Bogotá.

Subcomité de Participación. (2011). Informe metodológico de la implementación de la Ley 1448 de 2011. Ministerio de Justicia y del Derecho (Dirección de Justicia Transicional). Bogotá.

Unidad Administrativa de Atención y Reparación a Víctimas. (2013). Resolución 0388 de 10 
de mayo de 2013. Protocolo de participación de víctimas del conflicto armado.

Zamora, Angélica. (2011). La participación de las víctimas en la Ley 1448 de 2011. usAID y Fundación Social. Bogotá.

\section{Entrevistas}

Todas fueron realizadas por el autor y la transcripción se conserva en su archivo personal.

Alejandra Saffon, funcionaria de la Dirección de Justicia Transicional del Ministerio de Justicia y del Derecho. Bogotá, enero 25 de 2012.

Alfonso Castillo, líder de víctimas de crímenes de Estado. Bogotá, octubre 24 de 2012.

Ángel María, líder de víctimas del departamento de Arauca. Bogotá, octubre 26 de 2012.

Angeliza Zamora, investigadora del Área de Incidencia en Políticas Públicas de la Fundación Social y funcionaria pública de la Unidad Administrativa Especial de atención y Reparación Integral a las Víctimas. Bogotá, enero 12 de 2012.

Diana Ahumada. Presidencia de la República. Bogotá, octubre 24 de 2012.

Edwin Mendoza, líder de víctimas del departamento de Huila. Bogotá, octubre 25 de 2012.

Ernestina Martínez Caballero, líder de víctimas del departamento de César. Bogotá, octubre 26 de 2012.

Hernán Rocha, líder de víctimas representante de la organización Corporación Sociedad Activa. Bogotá, octubre 24 de 2012.

Juliana Vargas, investigadora del CIJUS, experta la participación de mujeres desplazadas. Bogotá, febrero 20 de 2012.

Leonel Uribe Hernández, líder de víctimas del departamento de Boyacá. Bogotá, octubre 25 de 2012.

Tania Bohórquez, líder de víctimas del departamento de Sucre. Bogotá, octubre 24 de 2012. 